\title{
Percepções e formação de acadêmicos em Engenharia Civil sobre risco e sua gestão
}

\author{
Carlos Guilherme Rocha ${ }^{1}$ \\ Letícia Pereira Gabriel ${ }^{2}$
}

\section{RESUMO}

Este artigo analisa como estudantes concluintes do curso de Engenharia Civil do CEFET-MG, campus Varginha, lidam com e percebem "riscos" em sua formação profissional. O propósito é analisar, no discurso desses acadêmicos, a representação de "risco" e conceitos que o circundam. De abordagem construtivista, esta observação foca em como fatores sociais e políticos são encarados pelos acadêmicos como pertinentes, ou não, à gestão dos riscos. Para realizar a análise, apresenta-se comentário sobre como os campos da Engenharia e das Ciências Sociais convergiram nas últimas décadas, levando à formação das "ciências cindínicas" e à institucionalização de propostas para gestão de risco, a partir de uma compreensão ampliada, que toma os riscos não apenas como probabilístico, mas que compreende outras dimensões, como condições sociais, memória e relações de trabalho. Evidenciou-se que os novos profissionais partilham de um paradigma tecnocrático de Engenharia que leva à condução objetivista e probabilista da gestão e análise de riscos. Dessa forma, aspectos éticos, condicionamentos sociais e a complexidade dos interesses humanos envolvidos são obliterados na abordagem profissional.

Palavras-chave: Riscos. Engenharia Civil. Percepção.

\footnotetext{
${ }^{1}$ Graduado em História pela Universidade Federal de São João Del-Rei - UFSJ. Mestre em História pela Universidade Estadual de Campinas - UNICAMP e Doutor em História pela Universidade Federal Fluminense - UFF. Atualmente é professor e pesquisador do Centro Federal de Educação Tecnológica de Minas Gerais CEFET, Campus Varginha, MG, Brasil. E-mail: carlosgrocha@ cefetmg.br.

${ }^{2}$ Graduanda em Edificações pelo Centro Federal de Educação Tecnológica de Minas Gerais - CEFET, Campus Varginha, MG, Brasil. E-mail: leticia.p.gabriel@ hotmail.com.
} 


\title{
Perceptions and academic qualification of civil Engineering Students about risk and its management
}

\begin{abstract}
This article analyzes how Civil Engineering senior students at CEFET-MG, campus Varginha, deal with and perceive "risks" in their professional qualification. The purpose is to analyze, in the speech of these academics, the representation of "risk" and concepts that surround it. In a constructivist approach, this observation focus on how social and political factors are viewed by academics as pertinent, or not, to risk management. In order to carry out the analysis, it is presented a comment on how the fields of engineering and social sciences have converged in the last decades, leading to the formation of "scindinic sciences" and the institutionalization of proposals for risk management, based on an expanded understanding, which takes risks not just as probabilistic, but that comprises other dimensions, such as social conditions, memory and work relationships. It became evident that the new professionals share a technocratic paradigm of Engineering, which leads to an objectivist and probabilistic approach to risk management and analysis. Thus, ethical aspects, social conditions and the complexity of the human interests involved are obliterated in the professional approach.
\end{abstract}

Keywords: Risks. Civil Engineering. Perception.

Artigo recebido em: 26/04/2021

Aceito em: 09/06/2021 


\section{CONCEITO DE RISCO E SUA GESTÃO}

O conceito de risco pode ser baseado em diversos fatos e apresentar mais de uma interpretação. Basicamente ele vem da incerteza entre a segurança ou a destruição de algo. Assim, é tomado como uma possibilidade tangente a todos os empreendimentos humanos.

O termo "risco" surgiu no início da modernidade, referindo-se a eventos que fugiam ao controle de mulheres e homens, tornando-se potenciais causadores de danos humanos, materiais e econômicos. A partir do século XVIII, com o Iluminismo, cientistas e técnicos passaram a trabalhar no sentido de prevenir esses eventos, orientados pela concepção que a humanidade poderia dominar, plenamente, todos os eventos (LUHMANN, 1993, p. 10-13). As engenharias foram símbolos desse processo. Caberia às engenheiras e aos engenheiros seguir normas técnicas, que garantissem a segurança e o benefício de seus produtos. O risco passou a ser entendido como uma dimensão previsível, calculável e, consequentemente, controlável pelos profissionais de engenharia. Esse paradigma, portanto, tomava os riscos como objetivos, passíveis de serem identificados e eliminados.

No entanto, na mesma medida que soluções eram produzidas, novos problemas eram identificados e percebidos tanto no campo científico quanto socialmente. Nas décadas de 1970 e 1980, a questão climática e ambiental, o contato cotidiano com elementos químicos e a energia nuclear passaram a ser vistos por muitos como perigos que já afetavam a humanidade (JASANOFF, 1990, p. 20-21). Mesmo em áreas de conhecimento tradicionais, como a construção civil, pesquisas mostram como o número de sinistros se mantém estáveis nas últimas sete décadas, apesar da instalação de normas técnicas e padrões de segurança (DO CARMO, 2019, p. 119-147).

A partir da década de 1980, o campo das engenharias foi desafiado quanto à forma de tratar com os riscos em suas atividades. Os métodos probabilísticos tiveram seus limites afirmados, obrigando profissionais da engenharia a lidar com a incerteza inerente. Um dos principais pensadores a questionar o paradigma de tratamento de riscos foi o sociólogo alemão Ulrich Beck. O pressuposto de seu pensamento era que toda intervenção técnica ou tecnológica é permeada por incertezas, que implicam em potenciais riscos.

Em seu livro "Sociedade de Risco", Beck (2011) não apenas questionou os pressupostos sobre os quais a ciência e a tecnologia se assentavam em nossa sociedade, como indicou que essas mesmas bases colocavam a humanidade numa condição de risco global. 
Acontecimentos trágicos como em Bopal (1984), Chernobil (1986) e na Baía de Guanabara (1997 e 2000) fizeram com que sua crítica ressoasse pelo mundo.

De acordo com Beck, o modelo fragmentado de ciência e tecnologia, regido pelo imperativo da melhor relação custo-benefício faz com que se ignore politicamente efeitos nocivos existentes, mas que seriam incognoscíveis vistos pelo paradigma da técnica e da racionalidade pura. Beck propunha a formação de uma nova epistemologia, que lidasse com os processos técnicos e científicos como questões políticas, visando a supressão das causas de risco, pela dura limitação dos processos de inovação.

Nas décadas seguintes, o pessimismo de Beck tem sido criticado em variadas vertentes acadêmicas, tanto nas engenharias quanto nas ciências sociais. Mas um ponto de sua proposta se assentou, os riscos, bem como as ciências e as engenharias devem também ser observadas por uma ótica política.

Os riscos, tanto globais quanto locais, são tidos como manifestações produzidas por condições históricas e sociais. No campo das ciências sociais, constitui-se uma abordagem construtivista, baseada na ideia de governabilidade. Nesta, toma-se a ideia de que a incerteza é uma dimensão pertinente e não anulável em qualquer intervenção técnica ou científica. Assim, deve-se adotar uma gestão de riscos que trate essas manifestações como possíveis, diante de uma incerteza radical. A governabilidade dos riscos, portanto, não se trata apenas de evitar manifestações de desastres, mas adotar, de maneira sistemática e democrática, ações de mitigação, resiliência, conscientização e controle (LUHMANN, 1993; FURED, 2007; JASANOFF, 2010; MENDES, 2015). O mais importante é ter em conta os interesses humanos envolvidos em um determinado empreendimento.

Tal concepção resultou na formação do campo das “ciências cindínicas". Essa área de conhecimento pressupõe que riscos e desastres devem ser vistos por uma ótica sistêmica e global, focando em ações de redução de impacto e gestão de crises, portanto, a interdisciplinaridade é estrutural em tal perspectiva de estudo dos riscos (LOURENÇO, 2018).

Essa formulação não foi obra puramente do pensamento de filósofos e sociólogos. As engenharias responderam positivamente ao desafio colocado por Ulrich Beck, assumindo que sua atuação de intervenção no mundo é também política, permeada por questões éticas e sociais (ALMEIDA, 2004; LEVESON, 2004; SILVEIRA, 2007; AVEN, 2008; ALMEIDA, 2014; OLIVEIRA, 2014; FIGUEIREDO, 2015; MAES, DANN, CASPEELE, 2016; ZILBOVICIUS, PIQUEIRA, SZNELWAR, 2020). Um dos efeitos práticos disso é a 
International Organization for Standardization (ISO) assumir tal princípio, em sua norma 31000 , sobre gerenciamento de riscos. O que este e outros dispositivos propõem não é a supressão total de riscos, mas assumi-los e lidar com eles de forma positiva na busca de segurança e eficiência. Nessa perspectiva, os riscos são tomados de maneira ampla, assumindo que toda organização pode estar exposta a riscos, que podem gerar desde problemas financeiros a situações que coloquem a vida de trabalhadores e envolvidos em perigo.

\section{O LUGAR SOCIAL DO PROFISSIONAL DE ENGENHARIA E A GESTÃO DO RISCO}

Partindo desse ponto de vista, tecnologias e seus usos não são neutros. Especialmente quando se trata da gestão do risco, fica evidenciado como as decisões tomadas (para reduzir, evitar, controlar ou assumir) são essencialmente políticas. Desse modo é entendido que as engenheiras e os engenheiros, enquanto especialistas e produtores de tecnologia, assumam protagonismo em relação a tais decisões. Adotar uma postura crítica diante das inovações e utilizações dos recursos tecnológicos é também reposicionar os profissionais de engenharia na esfera pública, tornando-os agentes em decisões éticas sobre como as comunidades lidam com tecnologias (ASLAKSEN, 2013). Wang Dazhou sustenta que as práticas de engenharia não são apenas resultados de ações humanas, mas geradoras da própria humanidade. Com isso, reforça o engenheiro chinês, a atividade de engenheiras e engenheiros não diz respeito à predição do futuro (forecasting) mas sobre aventar possibilidades sobre esse futuro (foresighting) (WANG, 2018).

Como mostra Erik Aslaksen, o papel social dos profissionais de engenharia como "técnicos" não é um lugar natural, pode e deve ser modificado (ASLAKSEN, 2015 a). Diante do excesso de tecnologia (BYUNG-CHUL, 2017) em nossa volta e dos dilemas éticos que emergem a cada dia, é desejado e necessário um novo perfil de atuação das engenheiras e engenheiros. A gestão de riscos sociais e globais é uma das questões postas à mesa quando se discute esse tema. Para tanto, é necessário formar profissionais que estejam atentos à complexidade dos processos aos quais está inserido, pensando sua prática como um sistema 
"of objects humans, practices, and meanings instead of a mere assembly of mechanical and electronic equipment"3 (WANG, LI, CAO, 2018, p. 54).

Uma das evidências dessa demanda foi a criação da United Nations Office for Disaster Risk Reduction (UNDRR) [Escritório das Nações Unidas para a Redução do Risco de Desastres], no ano de 1999, diante do reconhecimento internacional da necessidade de construir comunidades mais seguras e resilientes a situações de risco coletivo. Uma das concepções orientadoras da UNDRR foi apresentada em seu último relatório, em 2019: o risco é sistêmico. Nesse sentido, é proposto uma mudança de paradigma, que deixe de enfatizar a gestão dos desastres, para focar na gestão de riscos, constituindo um entendimento das interações dinâmicas que levam a tal condição (UNDRR, 2019, p. 65). Nesse âmbito, engenheiros e engenheiras têm papel determinante, atuando de forma mais ampla, combinada e buscando novos tipos de soluções para evitar, precaver e resistir, construindo comunidades mais democráticas e empoderadas.

Em paralelo à ação filiada à ONU, a International Organization for Standardization (ISO) [Organização Internacional para Padronização] dedicou-se, no fim da primeira década do século XXI, a formular modelos para gestão de risco. Pautada nos fundamentos teóricos das ciências cindínicas, a ISO 31000, publicada em 2009, é um conjunto de princípios e orientações possível de ser aplicada a qualquer empreendimento e organização, seja privada, pública, coletiva ou individual. Por seu caráter geral e genérico, a ISO 31000 não é certificável (UNDRR, 2012, p. 70). Recentemente, a norma foi atualizada, com sua publicação pela Associação Brasileira de Normas Técnicas (ABNT).

A ISO 31000 pressupõe que todo empreendimento pode estar sujeito a influências que tornam seu resultado incerto, e adota tal definição de risco. Portanto, a gestão de risco é levar em conta os contextos internos e externos ao empreendimento, "incluindo o comportamento humano e os fatores culturais" (ABNT, 2018, p. 1). Entende-se o risco como uma possibilidade subjetiva e qualitativa. Isto fica evidente na orientação da norma para que sejam apreciados "fatores sociais, culturais, políticos, jurídicos, regulatórios, financeiros, tecnológicos, econômicos e ambientais, em âmbito internacional, nacional, regional ou local", também "relacionamentos, percepções, valores, necessidades e expectativas das partes interessadas externas" (Idem, p. 6).

${ }^{3}$ de objetos humanos, práticas e significados ao invés de uma mera reunião de equipamentos mecânicos e eletrônicos (tradução do autor). 
Os princípios expostos pela ISO 31000 igualmente se coadunam à bibliografia teórica sobre riscos, propondo o cuidado sistêmico de todas as fases possíveis: antes (precaução e prevenção), durante (situações emergenciais, resposta imediata à crise/perigo; socorro); depois (recuperação da catástrofe) (LOURENÇO; ALMEIDA, 2018, p. 25). A gestão das incertezas que podem causar efeitos não previstos deve ser integrada, isto é, parte de todo processo do empreendimento. Também deve ser uma gestão personalizada, que considera as influências específicas a qual aquele projeto está sujeito e como ele pode influenciar o contexto que está inserido. Nesse sentido, deve levar em conta pontos de vista e percepções variadas, visando melhor conscientização e melhores fundamentos para ação, tornando-se uma gestão inclusiva.

Para que tais princípios se sustentem é fundamental manter canais constantes de comunicação e consulta, que sejam dialógicos. A comunicação deve ser entendida como partilha de informações entre todos os interessados de um empreendimento, seja de forma direta ou indireta. Essa comunicação deve subsidiar as ações de forma a criar um senso de inclusão e propriedade para os possíveis afetados. "Isso permite que as organizações abordem explicitamente a incerteza na tomada de decisão, enquanto também asseguram que qualquer incerteza nova ou posterior possa ser levada em consideração à medida que ela surja" (ABNT, 2018, p. 8).

A partir de um diálogo democrático, que considere as múltiplas percepções e sensibilidades, analisadas criticamente, a gestão do risco proposta pela ISO 31000:2018 revê ações e responsabilizações. Diversas pesquisas mostram que o amplo diálogo sobre incertezas e riscos não leva ao pânico, sim ao desenvolvimento de relações solidárias, pautadas em confiança mútua (SLOVIC, 1987; FIGUEIREDO et. al., 2004; SLOVIC, et. al., 2004; MENDES, 2006; MENDES, TAVARES, 2009). Com isso, a avaliação de riscos pode levar a diversos caminhos, como à recusa, à prevenção, à precaução, à mitigação, à elaboração de estratégias de resiliência, até mesmo à assunção e à ampliação das situações de risco (ABNT, 2018, p. 13-14).

\section{ASPECTOS LEGAIS E INSTITUCIONAIS DA FORMAÇÃO EM ENGENHARIA CIVIL NO CEFET-MG}

A nível nacional, essa perspectiva se materializou nos últimos tempos, orientando novo tipo de formação para os profissionais de engenharia. No ano de 2019, o Conselho Nacional de Educação aprovou novas diretrizes curriculares para os diversos cursos de graduação na 
área. $\mathrm{O}$ documento defende a formação de um profissional que tenha visão integral e sistêmica, comprometido com valores constitucionais da democracia e da solidariedade. $\mathrm{O}$ parecer do Conselho Nacional de Educação aponta para o caminho que conflui com a nova perspectiva de gestão de riscos:

\begin{abstract}
A formação em Engenharia deve ser vista principalmente como um processo. Um processo que envolve as pessoas, suas necessidades, suas expectativas, seus comportamentos e que requer empatia, interesse pelo usuário, além da utilização de técnicas que permitam transformar a observação em formulação do problema a ser resolvido, com a aplicação da tecnologia (BRASIL, 2019 a, p. 29).
\end{abstract}

O artigo terceiro das novas Diretrizes aponta para diversas características que o egresso de uma graduação em engenharia deve ter, entre as quais destaca-se a necessidade de uma visão holística e humanista, baseada na crítica, reflexão, cooperação e ética. Na prática, a ideia é que a atuação profissional seja baseada no conhecimento e diálogo com as necessidades dos usuários, se opondo a um modelo essencialmente tecnocrático. Para tanto, é necessário "considerar os aspectos globais, políticos, econômicos, sociais, ambientais, culturais e de segurança e saúde no trabalho" (BRASIL, 2019 b, art. 30). Dentre as competências, os currículos nacionais de engenharia devem trabalhar para desenvolver a capacidade de análise e registro dos diversos contextos sociais, culturais, ambientais e econômicos, no sentido de "realizar a avaliação crítico-reflexiva dos impactos das soluções de Engenharia" (Idem, art. 4º, IV, e).

O reconhecimento da complexidade e dos condicionantes sociais seria, portanto, uma qualidade essencial para as engenheiras e os engenheiros do século XXI. Capazes de estabelecer uma comunicação de via dupla, não só para informar, mas que se pautem pelas demandas que emergem das comunidades, atuando com responsabilidade social.

Ordenado em tal orientação, o Projeto Pedagógico do curso (PPC) de Engenharia Civil do CEFET-MG, campus Varginha, indica como princípio a formação de cidadão que seja crítico, competente e solidário na sua prática profissional (BRASIL, 2019 c). A compreensão dos contextos socioculturais e o reconhecimento da complexidade que envolve ofício da engenharia são propostas fundamentais do projeto pedagógico. Essa proposta se alinha com as orientações de Erik Aslaksen, ao propor que ciência e engenharia não devem ser só tomadas de maneira funcional, mas como modos de interação humana com o mundo.

Um dos pontos mais enfatizados pelo PPC do curso de Engenharia Civil é a promoção de uma abordagem interdisciplinar e multidisciplinar que possibilite às engenheiras e aos 
engenheiros egressos participarem e liderarem projetos em equipes, a fim de dar conta de situações complexas. O ideal é formar profissionais que tenham visão sistêmica sobre a produção tecnológica, tendo em conta questões administrativas, sociais, econômicas e ambientais relativas à sua prática.

O objetivo principal da pesquisa é avaliar as concepções de "risco" entre estudantes concluintes do curso de Engenharia Civil do CEFET-MG, campus Varginha. A ênfase da análise será em como ao refletir sobre o tema, os acadêmicos consideram (ou não) condicionantes sociológicas, antropológicas, políticos, culturais e históricas como estruturantes de um projeto de engenharia, em especial na gestão dos riscos. Avalia-se sob quais paradigmas de engenharia e de segurança se dá a formação de futuras engenheiras e engenheiros civis.

Nesse sentido, será analisado o perfil do egresso em comparação às competências previstas no Projeto Pedagógico da instituição e nas Diretrizes Curriculares Nacionais para as engenharias. Assim, o projeto propõe uma reflexão sobre o papel político e social de profissionais de engenharia, como agentes nas discussões éticas e globais acerca da forma como a humanidade lida com as tecnologias.

\section{METODOLOGIA DE PESQUISA}

Para realizar a análise e comparação entre as concepções até agora expostas e a forma como futuros engenheiros civis se posicionam diante da questão dos riscos em sua prática profissional, as informações foram colhidas através de entrevistas com estudantes, do curso de Engenharia Civil no Centro Federal de Educação Tecnológica de Minas Gerais (CEFETMG), campus Varginha.

Todo procedimento de pesquisa e seus instrumentos foram previamente aprovados pelo Conselho de Ética em Pesquisa da instituição. Da mesma forma, todos os participantes estavam cientes sobre os objetivos do trabalho, confirmando sua participação com o preenchimento e assinatura de Termo de Consentimento Livre e Esclarecido.

As entrevistas foram de abordagem semiestruturada e eram compostas por perguntas que contextualizam, no primeiro momento, dados pessoais e informações sobre a formação acadêmica. $\mathrm{O}$ objetivo foi de salientar a identidade dos participantes como acadêmicos da área de Engenharia Civil, fazendo com que passassem a enfrentar as questões a partir deste ponto de vista (COHN, FEHR, MARÉCHAL, 2014; COHN, MARÉCHAL, NOLL, 2015). 
Foram questionados, o que achavam de sua formação acadêmica e quais conhecimentos julgavam mais importantes para um profissional de engenharia. Nesse mesmo sentido, os entrevistados foram demandados a falar quais suas áreas de interesse no campo da Engenharia Civil.

O roteiro de entrevista foi composto por 16 questões. Sua formulação se fez a partir da definição conceitual do tema a ser pesquisado, de forma a garantir coerência à investigação, em especial à análise das informações produzidas (MENDES, 2015, p. 69-71). No processo de criação, foram realizadas entrevistas teste, também com estudantes de Engenharia Civil, mas que não estavam em fase de conclusão do curso. Esta etapa permitiu a realização de ajustes pontuais ao instrumento e confirmou seu potencial para atingir aos objetivos propostos pela pesquisa (GOLDENBERG, 2004, p. 85-91).

Foram entrevistadas, entre os meses de julho e agosto de 2020, seis pessoas, sendo dois homens e quatro mulheres. Os estudantes estavam em etapa conclusiva do curso, estando entre o $9^{\circ}$ e o $11^{\circ}$ período. A faixa etária dos entrevistados era entre 22 e 34 anos. Alguns deles já tiveram experiência no mercado de trabalho da construção civil, através de estágios, projetos ou vínculo empregatício, enquanto outros não. As entrevistas foram realizadas através de chamadas de vídeo pelo Google Meet e tiveram duração média de 30 minutos, mas com variações consideráveis (entre 15 minutos e uma hora de duração) de acordo com os entrevistados.

As questões realizadas tinham por objetivo extrair dos acadêmicos o que pensavam e tinham como definição de risco. Além disso, as entrevistas também incluíam perguntas para a observação de quem eles acreditavam ser responsável pelos riscos de um projeto e quais são os fatores que podem causá-los. Foram feitas perguntas que levavam a discussões sobre quais seriam as funções do profissional de engenharia em uma empreitada e edificação, daí observando suas visões sobre técnica e ciência no exercício da profissional, bem como sobre a gestão democrática e tecnocrática e até seus pensamentos sobre a tendência de exposição aos riscos com o passar dos tempos. Foram igualmente demandas suas opiniões quanto ao papel das disciplinas de Ciências Sociais e Humanas no curso de Engenharia Civil.

Por fim, também houve análise quanto a relação entre riscos e vulnerabilidades sociais, do mesmo modo suas considerações sobre como as ciências humanas e a filosofia, presentes no currículo acadêmico, poderiam auxiliar na formação do engenheiro e quais eram suas contribuições para esses profissionais. 
Com o consentimento dos participantes, todas entrevistas foram gravadas. Dessa forma, foi realizada análise detalhada do material. Nessa etapa, criou-se uma planilha permitindo exame global e compacto das informações colhidas. A planilha foi constituída a partir de hipóteses levantadas previamente (paradigma tecnocrático, relação entre risco e vulnerabilidades sociais) e conceitos fundamentais (risco, gestão democrática), mas igualmente permitindo que novas aspectos e considerações surgissem. Com isso, foi possível extrair os principais pontos da entrevista e observá-los a partir daquilo que havia sido anteriormente estudado. Também houve uma comparação entre eles, proporcionando interpretação diante dos diferentes pontos de vista e experiências, viabilizando conclusões que levassem em consideração os diversos fatores citados nos diálogos. A seguir, as observações e conclusões realizadas.

\section{RESULTADOS E DISCUSSÃO}

A Lidar com aquilo que é incerto e não desejado não é uma situação simples, por isso não é de se estranhar respostas inseguras, marcadas por hiatos e parênteses. Porém o que foi notado, ao apresentar questões sobre riscos e a relação com a atividade de engenheiras e engenheiros, não foi mero receio, sim um deslocamento, como se fosse uma questão alheia ao campo da engenharia e, até então, não tivesse sido ponto de reflexão. O risco, segundo o Entrevistado 2, seria "como se fosse um alerta(...)para a pessoa saber que existe algo ali que pode sair do padrão". Nesse mesmo sentido vão as considerações da Entrevistada 6: "acho que todas as construtoras têm se atentado mais a essa parte de prever os riscos e se antecipar a eles, mas por falha humana as pessoas deixam de cumprir os quesitos de segurança e se expõem aos riscos."

Observa-se a prevalência de um paradigma de engenharia como atividade exata e objetiva, que trata como se todos os eventos pudessem ser previstos e controlados. Dessa forma, riscos são tidos como uma dimensão eliminável de qualquer projeto. Tal pressuposto não seria somente falho, como promovedor de mais situações de risco nas práticas de engenharia, pois a complexidade dos empreendimentos é negligenciada (LEVESON, 2004; SZNELWAR et. al., 2019, p. 5-7; AGOPYAN, 2019). A manifestação de riscos é, dessa forma, tratada a partir da simples causalidade, desconsiderando todo processo interativo sob o qual as intervenções técnicas e tecnológicas se sustentam (VALÊNCIO, 2018).

O engenheiro civil português José Simão do Carmo chama a atenção que devemos tomar já que "uma obra de construção civil nunca é inteiramente segura; por mais pequeno 
que seja, existe sempre algum risco associado" (DO CARMO, 2019, p. 109). Diante disso, o correto não é ignorar os riscos, mas gerir, compartilhar e minimizar. Desenvolvendo essa ideia, o acadêmico português sugere que as avaliações de risco devem levar em conta variáveis como ameaça (aquilo que pode causar dano), exposição (valor dos elementos sujeitos a risco) e vulnerabilidade (condição que envolve sensibilidade, percepção e capacidade em relação a situações de risco). Enquanto a primeira variável é de base probabilística, as outras duas são perpassadas por julgamentos morais e políticos, centrado nos indivíduos e grupos sociais envolvidos no empreendimento. Aqui se põe uma das primordiais questões da atividade de engenharia, formular problemas, não apenas fornecer respostas.

Ao dizer que engenheiras e engenheiros atuam na formulação de problemas, entendese que um projeto de engenharia atua na transformação da realidade, a partir de demandas, possibilidades, queixas e oportunidades produzidas socialmente. Isso faz com que a engenharia, diferente de ciência, não se atenha apenas a uma ética interna, mas possua uma dimensão fundamentalmente política, permeada por incertezas, ambiguidades e imprecisões (SILVA, PROENÇA, 2015; FIGUEIREDO, 2015).

No entanto, os acadêmicos consultados expressaram uma visão de engenharia como atividade técnica infalível. A Entrevistada 5 deixa isso explícito, ao afirmar que as falhas e situações de risco são derivadas quase sempre de erros humanos, pela não aplicação correta de aspectos técnicos, no que é acompanhada pela Entrevistada 6. Ao ser questionado se todo problema ou acidente é fruto de falha humana, o Entrevistado 1 afirmou diretamente: "De maneira alguma”. Depois de algum silêncio, refletiu sobre a situação: “[...], talvez sim [...] de uma certa maneira sim. Às vezes, é, a pessoa não tem qualificação técnica, ela... ...se coloca em situações de risco".

Destaca-se o fato de que nenhum dos entrevistados relacionou a avaliação e a gestão de riscos a vulnerabilidades sociais. Eles não fizeram referência a essas vulnerabilidades quando foram questionados sobre fatores de risco, o que os gerava e o que poderia ser feito para uma melhor gestão deles.

Vulnerabilidades socioeconômicas levam a exposições a riscos decorrentes da violência, exploração, falta de acesso ao saneamento básico, educação e saúde de qualidade, moradias precárias e fome, por exemplo. Assim, parte-se da compreensão que os riscos são frutos de processos de marginalização e exclusão social, não o contrário (MENDES, 2015, p. 73-76). Isso não quer dizer que se trate de aspectos técnicos e geofísicos como de segunda 
categoria na avaliação de riscos, mas que tais fatores sejam tomados em conjuntos a condicionantes sociais, culturais e políticas.

Ao invés disso, os acadêmicos manifestaram posição tecnocrática (VALÊNCIO, 2014). Dessa forma, associaram os riscos à falta de planejamento, à não aplicação correta de padrões estabelecidos, à tentativa de diminuição dos gastos, à falta de fiscalização e manutenção, à pressa quanto aos prazos e, especialmente, à mão de obra não qualificada. É possível perceber isso com a Entrevistada 3, por exemplo, que quando perguntada sobre o que auxilia na diminuição de riscos disse: "se existir muita fiscalização na área de segurança do trabalho, né, que é uma área da engenharia que tem que ser sempre muito bem cobrada, muito bem fiscalizada". "Qualquer técnica mal executada acarreta em um risco", destacou a Entrevistada 6. "A construção civil é uma área que traz muita mão de obra não qualificada... então nisso ela contribui para acidentes e diversos problemas geradas por falhas humanas", apontou um dos entrevistados, ao ser questionado sobre fatores de risco.

Os desastres na construção civil refletem a realidade da desigualdade social e fatores como a pobreza, raça, idade e região (GOMES, 2003; TAKAHASHI et. al., 2012; COCKELL, 2014). Analisando os danos já ocorridos, é possível perceber os perigos que parte da população está exposta. Mais do que isso, é perceptível a diferença alarmante entre os desastres ocorridos entre as diferentes classes. O desigual acesso aos recursos básicos, desenvolvimento econômico e modo de vida das populações mostram como muitos vivem diretamente expostos aos perigos e vidas marginalizadas. A análise de todos esses fatores pode resultar em muitos esclarecimentos quanto à gestão dos riscos e como as vulnerabilidades sociais a quais diversas pessoas estão expostas estão diretamente ligadas a isso.

A questão é compreender quais condições produzem erros de maneira sistemática. Cargas horárias elevadas, negligência no campo de trabalho, baixos salários, escolaridade reduzida, dentre outros, não foram elencados como questões que geram riscos, ficando tudo reduzido à falta de conhecimento e de atenção na aplicação de técnicas.

Essa característica fica expressa quando os acadêmicos foram interrogados sobre a função que a engenheira(o) deve exercer, para redução dos riscos: todos foram unânimes em falar sobre a importância da comunicação. Dessa forma, muitos deles classificaram a dinâmica da obra de uma forma unilateral e hierárquica, em que a profissional de Engenheira Civil deveria explicar para os outros o que deve ser feito naquela obra. A fala da Entrevistada 4 é exemplar: "quando você não apresenta essas informações ou não deixa transparente, a 
pessoa não vai entender mesmo, ela não é obrigada a entender de uma área, de um campo que ela não está envolvida, não estudou". Enquanto um polo domina o saber (o do engenheiro) o outro é completamente carente de conhecimentos. Compreensões semelhantes foram comuns durante as conversas. Uma das estudantes disse que a função do profissional de engenharia, na comunicação, é “dar uma teoria que a pessoa não tem”, outro declarou que seria, "conscientizar as pessoas que estão envolvidas".

Tais dizeres corroboram que a formação destes profissionais se dá sob bases tecnocráticas, pois compreendem que sua ação, de técnico e especialista, como essencialmente neutra e orientada por princípios exclusivamente objetivos oriundos do conhecimento científico. Assim, não apontaram para como o restante da sociedade influenciaria na produção de conhecimentos e consensos. Caberia apenas a engenheiras e engenheiros tomar as decisões, de forma exata ou o mais próximo possível a isso, e passar o conhecimento aos leigos. Nesse sentido, questionados sobre quem seria o principal responsável por problemas que poderiam ocorrer em uma obra, a maioria disse que seria o engenheiro ou a engenharia, por ser projetista e gestor da empreitada.

Para além da culpabilização individual, como de "um pedreiro ou mestre de obra, se ele não seguir o projeto", a única dimensão sistêmica levantada como potencializadora da manifestação de riscos, acidentes e ruínas é a econômica. A Entrevistada 4 indicou isso de forma indireta, afirmando que pode haver riscos quando o envolvido "não teve compromisso com a qualidade do material”. Para o Entrevistado 1 "essa questão de não querer investir dinheiro em projeto, ensaio [...], são pontos que afetam muito a segurança de uma edificação e gera muito risco". Além disso, esse mesmo acadêmico indicou que possivelmente o maior responsável por problemas e vícios em uma edificação é "quem administra a parte financeira da obra".

No entanto, a dimensão econômica de um empreendimento é tomada como alheia ao serviço técnico e objetivo do profissional de engenharia, não como parte constituinte do projeto. Uma das entrevistadas qualificou essa tensão de "uma economia burra", no sentido de que a redução dos custos leva ao impedimento da correta aplicação técnica.

Os acadêmicos estão plenamente corretos ao considerar que a ênfase na produção e no retorno financeiro imediato são fatores potencializadores de tragédias e falhas no processo de uma edificação, seja pela adoção de mecanismos negligentes a normas de segurança, materiais que não sejam adequados, ausência de estudos diagnósticos ou pela falta de manutenção (MULLAINATHAN, SHAFIR, 2020, p. 167-172). Porém, é importante 
salientar que essa submissão da engenharia aos interesses econômicos não é um dado, mas fruto de um determinado paradigma que "has developed and received its current characteristics as part of the capitalism system, and it is a role that can be changed"4 (ASLAKSEN, 2015 a, p. 34).

Por esse mesmo ângulo, Wang Guoyu, Li Lei e Cao Xu destacam que a forma como tradicionalmente as engenharias lidam com a questão da viabilidade, enfatizando a dimensão financeira e ignorando os impactos dos empreendimentos na vida de indivíduos envolvidos e afetados, baseia-se na ideia de que esse público não possui conhecimento genuíno e relevante. Ignora-se assim que todo processo de intervenção na realidade e de aceitação de uma tecnologia é perpassado por valores, não apenas por fatos empíricos (WANG, LI, CAO, 2018, p. 55).

Reforça a presença desse paradigma tradicional na formação em Engenharia Civil, as falas que indicam que o desenvolvimento tecnológico, por si só, seja capaz de eliminar desastres e riscos, como afirmou o Entrevistado 1: "as pessoas estão expostas a menos riscos devido a esse ponto, de surgimento de novas técnicas".

Indagados sobre a Filosofia e as Ciências Sociais e sua importância na formação de engenheiros, todos consideraram importantes, mas deram a entender que se trata mais de disciplinas extras do que algo essencial à sua formação durante o curso. Foi falado repetidas vezes sobre como as ciências humanas podem auxiliar na comunicação e gestão de pessoas, mas não como podem contribuir na tomada de decisões em uma obra, dissociando-as da "técnica". Exemplo na fala da Entrevistada 3, que diz: "acho muito importante [as disciplinas de Ciências Sociais e Filosofia], eu vejo elas como ótimas ferramentas para o curso, apesar do curso ser considerado, né... uma área mais exata, uma área mais lógica, eu acho que os cursos humanos são muito importantes, justamente por se tratar dessa parte de conscientização, de comunicação".

O Entrevistado 1 também ilustra essa opinião, quando fala que

[...] você ter essa noção da importância de saber conversar com todas as pessoas que estão relacionadas numa obra, numa construção [...], se você não tem uma boa relação com as pessoas, se você não sabe... levar a sua equipe de trabalho, a diferença que você tem de produção, de andamento da obra, é impressionante.

${ }^{4}$ desenvolveu e recebeu suas atuais características como parte do sistema capitalista, e é uma função que pode ser alterada (tradução do autor). 
Com isso, foi possível perceber que todos os entrevistados estabeleceram uma cisão das áreas, mostrando que a engenharia seria um curso "de exatas", mas que também precisava da comunicação e das ciências sociais. Dessa forma, eles mostraram a Engenharia Civil como um curso com disciplinas separadas, não como se todas elas estivessem em harmonia para garantir uma maior qualidade nas obras e nos projetos.

Assim, a perspectiva dos estudantes sobre os conhecimentos em humanidades e ciências sociais é de que seriam mecanismos para que os saberes técnicos, objetivos, por eles dominados se efetivem e cheguem a todos os interessados. A atuação do profissional de Engenharia não é vista de forma holística e sistêmica, como orientam as Diretrizes Curriculares Nacionais dos cursos de Engenharia, mas fracionada entre a produção técnica (atividade principal) e a gestão/comunicação de pessoas (exercício auxiliar).

É importante destacar que os acadêmicos entrevistados não se manifestavam como técnicos ideais, alheios às questões sociais que tangem seu futuro trabalho. A preocupação com a influência financeira nos resultados de um projeto é sinal disso. Outro aspecto, já destacado, é que todos ressaltaram a importância de uma boa comunicação no exercício de sua profissão, pois não basta ter a melhor solução, é necessário ser entendido e ouvido, ou, como declarou uma das futuras engenheiras, é preciso "atingir as pessoas da forma mais didática e acessível possível." Nesse sentido, destaca-se fala do Entrevistado 1: "Eu acho que esse é um ponto que a gente tinha que desenvolver mais na graduação, que é ter um pensamento mais humano [...], tanto nas questões de pensar o que aquilo que você vai construir vai trazer de benefício para a sociedade, você pensar no lado humano... nas relações de trabalho... nessa área da construção civil [...] a gente vê pouco disso, muito pouco.”

A reflexão feita pelo acadêmico acima aparece também na de seus colegas. Em diversos momentos os estudantes apontaram - mesmo que sem manifestação explícita - que a falta de articulação dos conhecimentos acadêmicos, especialmente pensando a prática profissional, é uma das principais carências do curso. Ao avaliar sua formação, um dos entrevistados declarou que considera o curso bom, "mas é muito voltado, se você pegar a grade curricular, para questões de cálculo, de projeto, de cálculo mesmo.” No mesmo sentido, o Entrevistado 2 disse: “A sensação que eu tinha era que... a gente é meio que preparado assim, a gente faz muito trabalho, mas tem coisa na rotina de engenheiro que a gente não é tão impulsionado assim a fazer [...] muitas vezes a gente fica condicionado a entregar trabalhos.” 
A Entrevistada 5, perguntada sobre quais conhecimentos julga mais importantes na formação em engenharia, afirmou: "o conhecimento que (...) não sei se julgo isso como um conhecimento, mas talvez uma habilidade, que acho que a pessoa tem que ter a habilidade de pegar, de se virar." Ou seja, a acadêmica toca em um dos pontos centrais da engenharia a capacidade para criar e resolver problemas, interferindo na realidade. No entanto, fica claro como ela parte de um modelo tecnicista, mantendo a divisão entre teoria e prática, sendo aquela do campo de sua formação superior, enquanto a aplicação caberia a engenheiras e engenheiros em suas atuações profissionais.

As preocupações éticas e sociais em torno da atuação profissional de engenheiras e engenheiros civis existem e foram repetidamente destacadas. No entanto, são tomadas como questões individuais ou de segunda ordem, não como componentes fundamentais de qualquer ação em engenharia. A complexidade social e o impacto político da tomada de decisões são alheios ao paradigma tecnocrático de suas formações. Assim, dimensões pertinentes à composição de um problema (sustentabilidade, impacto econômico, sujeição a riscos etc.) que antecedem ao ato de engenharia, flutuam de maneira errática, sem receberem a devida atenção e tratamento por parte dos profissionais, por não encontrarem lugar em um determinado paradigma. Ocorre fenômeno semelhante ao que Thomas Kuhn chamou de questão da "incomensurabilidade", ou seja, a dificuldade ou impossibilidade de comunicação entre certas ideias ou conceitos no seio de modelos técnicos e científicos, apesar de tratarem do mesmo objeto (KUHN, 2018).

Com ênfase na questão da segurança, a engenheira estadunidense Nancy Leveson sustenta a necessidade de se desenvolver novo paradigma, em que fatores sociais, culturais e políticos sejam tratados como parte dos sistemas de engenharia. Estes, enfatiza Leveson, não são meros artefatos tecnológicos, mas reflexos de procedimentos, administração, estrutura e cultura das organizações de engenharia. É necessário que os engenheiros e as engenheiras estejam atentos a como dimensões políticas e éticas (propósitos, objetivos, critérios) são também componentes do processo de engenharia (LEVESON, 2011).

A formação demasiada teórica, que dialoga pouco com situações reais, foi levantada pelos acadêmicos. Como destaca a Entrevistada 5, esse não é um problema apenas da sua formação, mas do nosso sistema educacional como um todo. Dessa forma, muitos declararam suas atividades de estágios curriculares como fundamentais para adquirir segurança e "para ver como são as coisas no real", afirmou o Entrevistado 1. Tal declaração, a princípio, caminha no mesmo sentido das Diretrizes Curriculares de Engenharia, que 
indicam os estágios como forma para que os estudantes "se envolvam efetivamente em situações reais que contemplem o universo da Engenharia" (BRASIL, 2019 b, art. 11, § 2º ). A política de formação de engenheiras e engenheiros é clara ao apontarem os estágios como uma etapa de consolidação, ativamente articulada com os aprendizados ao longo do curso. Contudo, o que se percebe nas declarações dos estudantes é um quadro bem diferente, de dicotomia expressa entre formação teórica e atuação prática, como dimensões que pouco dialogam.

\section{CONCLUSÃO}

Como já foi dito, nenhum dos entrevistados associou diretamente vulnerabilidades sociais aos desastres, riscos e potenciais problemas que se manifestam na construção civil. Isso se mostra preocupante, visto que seria de grande importância que os profissionais da área pudessem atuar frente a esses fatores. É necessário termos ciência de como as desigualdades socioeconômicas colocam parcela da população em grande exposição aos riscos, e que tal processo não se resume apenas a falhas individuais, mas são frutos de condições sistêmicas. A partir do momento que esses acontecimentos são relacionados, a análise e gestão dos riscos podem ser feitas de forma mais abrangente, resultando em alertas mais eficientes, redução das ameaças e inclusão democrática.

É imperativo compreender que acidentes de trabalho, tão frequentes e graves na construção civil, não dizem respeito apenas ao empreendimento e organização no qual o evento ocorreu, mas são questões de interesse coletivo, pois dizem respeito à saúde pública (MALTA et. al., 2017) e ao orçamento do Estado (SANTANA et. al., 2006). Da mesma forma, destaca-se o déficit habitacional de cerca de 6 milhões de moradias, registrado no ano de 2019 (FUNDAÇÃO JOÃO PINHEIRO, 2021), não atendendo à implementação do direito à moradia, consagrado no Artigo $6^{\circ}$ da Constituição Federal brasileira.

As ciências sociais e a filosofia, na formação acadêmica em engenharia, por sua vez, podem ser essenciais para que haja um pensamento crítico, que leve em conta diferentes visões da situação e a complexidade das relações sociais, possibilitando mais respostas que podem ajudar a lidar melhor com as incertezas, por mais que elas não deixem de existir (ASLAKSEN, 2019 b, p. 164). É fundamental que as diferentes áreas que estão presentes na formação de engenheiras e engenheiros sejam consideradas e relacionadas. Como destaca o professor Li Bocong, a engenharia é uma atividade fundamentalmente social, pois se baseia na ideia de "valor de uso" de seus resultados, portanto, uma dimensão ética e política, 
pautada em escolhas e fatores sociais que não se resumem apenas aos profissionais da área, mas a toda comunidade afetada e envolvida em um empreendimento de engenharia (LI, 2018).

Constituir novas bases, que incluam um novo vocabulário e questões, que levem em conta questões éticas e sociais, não é apenas uma mudança de ponto de vista na resolução de problemas. Mais que isso, trata-se de incluir novos agentes, percepções e sensibilidades e conceber a engenharia como possibilidade de abertura para outras condições de vida em sociedade.

\section{REFERÊNCIAS}

ABNT. Associação Brasileira de Normas Técnicas. Projeto de Revisão ABNT NBR ISO 31000. 2018.

AGOPYAN, Vahan. A engenharia não é uma ciência exata. Jornal da USP (on-line), 21 de fevereiro de 2019. Disponível em: https://jornal.usp.br/institucional/a-engenharia-nao-euma-ciencia-exata/.

ALMEIDA, Betâmio. Incertezas e riscos no contexto da Engenharia. In: Congresso da Água, Lisboa, 2004.

ALMEIDA, Betâmio. Análise e gestão de risco, a participação da Engenharia. Ingenium, n. $142,2014$.

ASLAKSEN, Erik. The Engineering Paradigm. International Journal of Engineering Studies, v. 5, n. 2, 2013.

ASLAKSEN, Erik. The Relationship Between Engineers and Society: is it currently fulfilling its potential? An invited discourse. Journal and Proceedings of the Royal Society of New South Wales, v. 148, ns. 455/456, 2015 a.

ASLAKSEN, Erik. The Future of Engineering. Journal and Proceedings of the Royal Society of New South Wales, v. 148, ns. 457/458, 2015 b.

AVEN, Terje. Risk Analysis. Assessing uncertainties beyond expected values and probabilities. Chichester (Ing): John Wiley \& Sons, 2008.

BECK. Ulrich. Sociedade de Risco: rumo a uma outra modernidade. São Paulo: Editora 34, 2011.

BRASIL. Ministério da Educação, Conselho Nacional de Educação. Parecer 01/2019. Diário Oficial da União. 22 de abril de 2019 a. Disponível em: http://portal.mec.gov.br/index.php?option=com_docman\&view=download\&alias $=109871$ pces001-19-1\&category_slug=marco-2019-pdf\&Itemid=30192. 
BRASIL. Ministério da Educação, Conselho Nacional de Educação. Resolução 02/2019. Diário Oficial da União. 26 de abril de 2019 b. Disponível em: http://www.in.gov.br/web/dou/-/resolu\%C3\%87\%C3\%830-n\%C2\%BA-2-de-24-de-abrilde-2019-85344528.

BRASIL. Ministério da Educação. Projeto Pedagógico do curso de Engenharia Civil da unidade de Varginha do CEFET-MG. Varginha, 2019 c.

BYUNG-CHUL Han. Sociedade da Transparência. Petrópolis: Vozes, 2017.

COCKELL, Fernanda. Idosos aposentados no mercado de trabalho informal: trajetórias ocupacionais na construção civil. Psicologia e Sociedade, v. 26, n. 2, 2014.

COHN, Alain; FEHR, Ernst; MARÉCHAL, Michel. Business culture and dishonesty in banking industry. Nature, v. 516, 2014.

COHN, Alain; MARÉCHAL, Michel; NOLL, Thomas. Bad boys: how criminal identity salience affects rule violation. Review of Economic Studies, v. 82, 2015.

DO CARMO, José Simão. Riscos inerentes à construção civil. In: LOURENÇO, Luciano; DE CASTRO, Fátima. Catástrofes antrópicas. Uma aproximação integral. Coimbra: Imprensa da Universidade de Coimbra, 2019.

FIGUEIREDO, Elisabete et al. Conviver com o risco: a importância da incorporação da percepção social nos mecanismos de gestão do risco de cheia no concelho de Águeda. In: Anais do VIII Congresso Luso-Afro-Brasileiro de Ciências Sociais. Coimbra: Universidade de Coimbra, 2004.

FIGUEIREDO, José. A Engenharia no tempo em que a especialização se dilui na equipa. Ingenium, n. 145, 2015.

FUNDAÇÃO JOÃO PINHEIRO. Deficit habitacional no Brasil - 2016-2019. Belo Horizonte: Fundação João Pinheiro, 2021.

FURED, Frank. The only thing we have to fear is the 'culture of fear' itself. Spiked, abril, 2007.

GOMES, Rafael. A produção social do infortúnio: acidentes incapacitantes na construção civil. Dissertação (mestrado). Rio de Janeiro: Escola Nacional de Saúde Pública - Fiocruz, 2003.

GOLDENBERG, Mirian. A arte de pesquisar: como fazer pesquisa qualitativa em Ciências Sociais. Rio de Janeiro: Record, 2004.

JASANOFF, Sheila. The fifth branch. Science advisers as policymakers. Cambridge (EUA): Harvard University Press: 1990.

JASANOFF, Sheila. A new climate for society. Theory, culture \& society, n. 2-3, v. 27, 2010. 
KUHN, Thomas. A estrutura das revoluções científicas. São Paulo: Perspectiva, 2018.

LEVESON, Nancy. A new accident model for engineering safer systems. Safety Science, v. 42, abril, 2004.

LEVESON, Nancy. Engineering a safer world. Systems thinking applied to safety. Cambridge (EUA): MIT Press, 2011.

LI Bocong. On relationships between history and philosophy of Engineering. In: MITCHAM, Carl [ed.]. Philosophy of Engineering. East and West. Boston: Springer, 2018.

LOURENÇO, Luciano. Introdução. In: LOURENÇO, Luciano; AMARO, António [coords.]. Riscos e crises. Da teoria à plena manifestação. Coimbra: Imprensa da Universidade de Coimbra, 2018.

LOURENÇO, Luciano; ALMEIDA, Betâmio. Alguns conceitos à luz da teoria dos riscos. In: LOURENÇO, Luciano; AMARO, António [coords.]. Riscos e crises. Da teoria à plena manifestação. Coimbra: Imprensa da Universidade de Coimbra, 2018.

LUHMANN, Niklas. Risk: a sociological theory. Nova Iorque: De Gruyter, 1993.

MAES, Marc; DANN, Markus; CASPEELE, Robby. Unknowable unknowns and extremes-beyond-extremes in decision making: myth, apology, or opportunity? In: International Forum on Engineering decision making, Stoos (Suíça), 2016.

MALTA, Deborah et. al. Acidentes de trabalho autorreferidos pela população adulta brasileira, segundo dados da Pesquisa Nacional de Saúde, 2013. Ciência \& Saúde Coletiva, v. 22, n. 1, 2017.

MENDES José Manuel; TAVARES, Alexandre. Building Resilience to Natural Hazards. Practices and Policies on Governance and Mitigation in the Central Region of Portugal. In: MARTORELL, Sebastian et. al. [orgs.]. Safety, Reliability and Risk Analysis. Vol. 2, Theory, Methods and Applications. Leiden: CRC Press/Balkema, 2009.

MENDES, José Manuel. Sociologia do risco. Uma breve introdução e algumas lições. Coimbra: Universidade de Coimbra, 2015.

MENDES, Patrícia Brant. Percepção de risco ambiental em cortiço vertical: uma metodologia de avaliação. Universidade de São Paulo. Tese (doutorado). São Paulo: Faculdade de Saúde Pública, 2006.

MULLAINATHAN, Sendhil; SHAFIR, Eldar. Escassez: uma nova forma de pensar a falta de recursos na vida das pessoas e nas organizações. Rio de Janeiro: Best Business, 2020.

OLIVEIRA, António. Análise e gestão do risco e normativos de segurança. O papel do engenheiro. Ingenium, n. 142, 2014.

SILVA, Édison; PROENÇA JR., Domício. Não ser não é não ter: Engenharia não é Ciência (nem mesmo ciência aplicada). In: PROENÇA, Adriano et. al. Gestão da inovação e competitividade no Brasil: da teoria à prática. Porto Alegre: Bookman, 2015. 
SILVEIRA, Marcos A. Controle e automação: história e caracterização. In: AGUIRRE, Luis (org.). Enciclopédia de Automática. São Paulo: Edgard Blücher, 2007, v. 1.

SLOVIC, Paul. Perception of Risk. Science, n. 4799, v. 236, 1987.

SLOVIC, Paul et. al. Risk as analysis and risk as feelings: some thoughts about affect, reason, risk, and rationality. Risk Analysis, n. 2, v. 24, 2004.

SZNELWAR, Laerte et. al. Brumadinho: entre a prudência e probabilidade, a tragédia. Revista Brasileira de Medicina do Trabalho, v. 17, 2019.

TAKAHASHI, Mara et. al. Precarização do trabalho e risco de acidentes na construção civil: um estudo com base na Análise Coletiva do Trabalho (ACT). Saúde e Sociedade, v. 21, n. $4,2012$.

UNDRR. United Nations Office for Disaster Risk Reduction. Como construir cidades mais resilientes. Genebra: UNDRR, 2012.

UNDRR. United Nations Office for Disaster Risk Reduction. Global assessment report on disaster risk reduction. Genebra: UNDRR, 2019.

VALÊNCIO, Norma. A visão do risco pela sociologia. In: LOURENÇO, Luciano; AMARO, Antônio [coords.]. Riscos e crises. Da teoria à plena manifestação. Coimbra: Imprensa da Universidade de Coimbra, 2018.

VALÊNCIO, Norma. Desastres: tecnicismo e sofrimento social. Ciência e Saúde Coletiva, n. 9 , v. 19, 2014.

WANG Dazhou. Toward an experimental philosophy of Engineering. In: MITCHAM, Carl [ed.]. Philosophy of Engineering. East and West. Boston: Springer, 2018.

WANG Guoyu; LI Lei; CAO Xu. Feasibility and acceptability in Engineering. In: MITCHAM, Carl [ed.]. Philosophy of Engineering. East and West. Boston: Springer, 2018.

ZILBOVICIUS, Mauro; PIQUEIRA, José; SZNELWAR, Laerte. Complexity engineering: new ideas for engineering design and engineering education. Anais da Academia Brasileira de Ciências, v. 92, 2020. 